\title{
Vicarious Trauma in Mental Health Professionals Following the 9/11 Terrorist Attacks
}

\author{
Gertie Quitangon ${ }^{1 *}$, Kate St. Cyr ${ }^{2}$, Charles Nelson ${ }^{3}$, Steven Lascher ${ }^{4}$, Lea DiFrancisci ${ }^{1}$ and Spencer Eth ${ }^{5}$ \\ ${ }^{1} \mathrm{NYU}$ School of Medicine, Psychiatry, New York, USA \\ ${ }^{2}$ Research Associate ,Operational Stress Injury Clinic, Parkwood Hospital ,London, Ontario, Canada \\ ${ }^{3}$ Psychologist, Operational Stress Injury Clinic, Parkwood Hospital, Hobbins Building, 3rd Floor. Room H 3015, London, Ontario, CANADA \\ ${ }^{4} \mathrm{CEO}$, Evidence Impact Strategies, USA \\ ${ }^{5}$ Associate Chief of Staff for Mental Health,Department of Veterans Affairs,Miami VA Healthcare System
}

\begin{abstract}
Introduction: Some research evidence has suggested that mental health clinicians who provide services following massive disasters are at risk for developing symptoms of vicarious trauma (VT). This pilot study was conducted following the unprecedented terrorist attacks in New York City on September 11, 2001.

Objectives: 1) To identify risk and protective factors of VT in a sample of mental health professionals who provided services to victims of 9/11. 2) To compare and contrast the findings of the survey with other published studies.

Method: A group of mental health professionals who provided services to New York City residents affected by $9 / 11$ were surveyed on the first year anniversary of the terrorist attacks. Risk and protective factors of VT were identified using correlation and chi-squared analyses. Findings of this survey were compared with other published studies on VT in mental health clinicians who worked with 9/11 survivors.

Results: History of personal trauma, fewer years of professional experience, fewer hours of individual supervision, and larger caseloads were identified as probable risk factors for VT.

Conclusions: An increased risk of VT was associated with a number of work-related and personal variables. Enhanced professional and social supports may decrease the risk of VT in mental health professionals who provide services in the context of disasters and mass psychological trauma.
\end{abstract}

Keywords: Vicarious trauma; PTSD phenomenology; Risk and protective factors; Terrorism

\section{Introduction}

The 9/11 terrorists attacks on the World Trade Center in New York City resulted in the loss of many lives, and a profound disturbance in self-perceived safety nationwide [1]. The psychological impact of the traumatic event has been documented in different populations [25] including first responders/recovery workers at Ground Zero [6,7]. However, the impact of providing mental health services to those traumatized by $9 / 11$ on the clinicians has been less widely studied.

Evidence-based psychotherapies for posttraumatic stress disorder (PTSD), such as prolonged exposure (PE) therapy and cognitive processing therapy $(\mathrm{CPT})$, involve the detailed retelling of traumatic events, which expose psychotherapists to potentially distressing narratives [8]. Research suggests that providing psychotherapy to trauma victims may produce PTSD-like symptoms and cognitive changes in psychotherapists themselves $[9,10]$. This phenomenon has been described as vicarious traumatization (VT). Over the past few decades, researchers have attempted to explain the occurrence of VT, which is considered different from counter transference or burnout [11]. It has been suggested that VT in psychotherapists may be caused by the clinicians' internal reactions to the imagery and intrusive thoughts produced by listening to repeated, and often vividly detailed accounts of their clients' traumatic experiences [12-14]. Jenkins and Baird [15] have suggested that VT alters the views and relationships of the psychotherapist, aligning these outlooks more similarly with those of the traumatized client, thereby differentiating itself from counter transference, which is considered to be a contained, shortterm response [12], and from burnout, which stems from a work- related situation rather than an interpersonal interaction [14]. VT may be expressed as anxious or depressive thoughts, somatic complaints, the presence of intrusive thoughts and images, emotional numbing, difficulties with intimacy, and a heightened sense of distrust (Table 1). Although not all individuals will experience all symptoms, the psychological consequences of VT can have deleterious effects on the personal and professional life of the psychotherapist [16-18].

VT in clinicians who provide mental health services to victims of trauma, such as sexual trauma survivors, offenders [19-21] and military veterans $[22,23]$ has been well documented. VT has also been documented in those who provide mental health services to victims of large-scale catastrophes, such as hurricanes, earthquakes, and civil war [24,25]. Additionally, VT has been identified in cohorts of non-mental health providers such as peacekeepers and humanitarian aid workers [26], child protection workers [27,28], and first responders and law enforcement officers [29]. This paper studies a group of mental health clinicians who provided a wide range of services in the aftermath of the unprecedented mass traumatic events of September 11, 2001.

*Corresponding author: Gertie Quitangon, NYU School of Medicine, Psychiatry 220 Riverside Blvd \#20-U New York, NY 10069, Tel: 01-212-721-0302; E-mail: gquitmd@gmail.com

Received June 21, 2016; Accepted July 11, 2016; Published July 20, 2016

Citation: Quitangon G, St. Cyr K, Nelson C, Lascher S, DiFrancisci L, et al. (2016) Vicarious Trauma in Mental Health Professionals Following the 9/11 Terrorist Attacks. J Ment Disord Treat 2: 118. doi:10.4172/2471-271X.1000118

Copyright: (c) 2016 Quitangon G, et al. This is an open-access article distributed under the terms of the Creative Commons Attribution License, which permits unrestricted use, distribution, and reproduction in any medium, provided the original author and source are credited. 


\begin{tabular}{|c|c|c|}
\hline Emotional & Cognitive & Physical \\
\hline Less grounded & Feeling unworthy of love & Feeling unsafe \\
\hline Overwhelmed & Feeling unloved & $\begin{array}{c}\text { Intrusive visual, auditory, sensory, and } \\
\text { olfactory imagery }\end{array}$ \\
\hline Frustrated & Question right to be alive/happy & Disconnected from loved ones \\
\hline Unbearable anxious & Self- loathing & Eruptions of anger \\
\hline Unable to experience pleasure & Poor decision-making & Intolerant \\
\hline $\begin{array}{c}\text { Emotionally numb Emotionally closed } \\
\text { Despair }\end{array}$ & Feeling like a failure Lack of trust Cynical & Prom significant others \\
\hline Resentful Exhausted Flooding reminders & Intrusive imagery & Poor judgment Loss of control \\
Nightmares
\end{tabular}

Adapted from Saakvitne and Pearlman [40].Transforming the pain: A workbook on vicarious traumatization for helping professionals who work with traumatized clients New York. Norton.

Table 1: Vicarious Traumatization Symptomatology.

\section{Methods}

One year following the $9 / 11$ terrorist attacks, a written survey was completed by 35 mental health professionals at St. Vincent's Hospital Manhattan (SVH), a teaching hospital in downtown New York City. Informed consent and approval from the institutional review board was obtained.

The survey consisted of two standardized tools [30], Impact of Event Scale - Revised [31], Trauma Symptom Inventory [32] and a Personal Questionnaire. The questionnaire inquired about caseloads, including involvement with victims of the $9 / 11$ terrorist attacks in New York City immediately following the event and one year later; frequency of individual supervision received; demographic information such as age, religious participation, and marital status; and psychiatric history, including past personal trauma, and symptoms of depression and anxiety prior to the $9 / 11$ terrorist attacks.

Correlation analyses were conducted to estimate the association between TSI subscale scores, psychiatric variables, and demographic variables, while chi-square analyses were used to identify differences between groups of participants.

On the 10th year anniversary of $9 / 11$, a systematic literature review on VT and mental health professionals who provided services to $9 / 11$ victims from 2001-2011 was conducted.

\section{Results}

\section{Literature review}

Ten years after 9/11, there were over 300 studies on VT, secondary traumatic stress and other related concepts. However, only five studies that focused on 9/11 examined similar variables of interest and allowed comparison with cohort studies from the SVH study [33-37] (Table 1). The majority of the studies reviewed examined the relationships between both personal (i.e. age, marital status, history of trauma) and professional factors (i.e., years of experience, caseload, hours of supervision) and symptoms of traumatic stress among mental health workers.

\section{Risk factors}

Personal trauma history: In the SVH survey, a history of trauma was significantly associated with post-9/11 symptoms. Of those who had no previous exposure to traumatic events, 35\% reported experiencing some post-9/11 symptoms of psychological distress; while $67 \%$ of participants who acknowledged a history of trauma described experiencing post-9/11 symptoms. Symptoms include increased anxious arousal, depression, anger/irritability, intrusive experiences, defensive avoidance, sexual concerns, and tension reduction behaviors. A history of past trauma also emerged as a significant predictor of traumatic stress which is consistent with the results of the Adams and colleagues study [33]. However, personal trauma history was not significantly related to secondary traumatic stress in the Creamer study [35].

Symptoms of depression and anxiety before and after 9/11: Individuals who reported experiencing depressive symptomatology prior to the $9 / 11$ terrorist attacks had significantly higher IES-r intrusion scores than those who did not report depression symptoms before $9 / 11\left(X^{2}=6.04, p=0.014\right)$. Post-9/11 symptoms of depression or anxiety were also positively correlated with a number of TSI subscales (Table 2). Of the five studies reviewed for comparison purposes, none evaluated history of depression and anxiety as a risk factor for VT.

Caseload: In the SVH study, clinicians who reported having 9/11 rescue workers in their caseloads had elevated intrusion scores. The Creamer and Liddle [35] study, which surveyed eighty clinicians from 28 states, as well as Washington, DC and Alberta, Canada, revealed that disaster mental health workers who had a caseload of current and past trauma victims including children, firefighters, and clients with morbid material, showed higher symptoms of secondary traumatic stress. In addition, they also found that those with heavier trauma caseload prior to $9 / 11$ had significantly higher secondary traumatic stress symptomatology after $9 / 11$.

Proximity to ground zero: Proximity to Ground Zero was an implicit variable in the study as SVH was only three miles north of the World Trade Center. Most of the respondents were at the medical center when the attacks occurred and over $90 \%$ immediately provided services to $9 / 11$ trauma victims. The Eidelson et al. [37] study of 592 psychologists in NY, NJ, CT and PA specifically examined the impact of distance from Ground Zero on clinicians. They found that those who worked closer to Ground Zero reported higher work related stress and stronger feelings of being unprepared. These respondents also had the highest percentage of caseload affected by $9 / 11$. Colarossi et al. [34] found that, among the 777 social work students and MSW practitioners in the NY metropolitan area surveyed, those living within 10 miles of the World Trade Center site reported increased symptoms of depression, anxiety, somatization and traumatic stress. They also found that those who were displaced from work after the attack presented with significantly higher somatic symptoms.

Anniversary reaction: The SVH study was conducted on the first year anniversary of $9 / 11$, and as previously reported, clinicians who reported post $9 / 11$ symptoms of depression and anxiety scored higher on the TSI subscales of intrusive experiences, defensive avoidance, 


\begin{tabular}{|c|c|c|}
\hline Independent variable & TSI subscale & $\mathbf{r}$ \\
\hline \multirow{4}{*}{ Past trauma } & Anger/irritability & 0.45 \\
\cline { 2 - 3 } & Anxious arousal & 0.31 \\
\cline { 2 - 3 } & Defensive avoidance & 0.35 \\
\cline { 2 - 3 } & Depression & 0.39 \\
\hline \multirow{3}{*}{ Post 9/11 depression or } & Intrusive experiences & 0.32 \\
\hline \multirow{3}{*}{ anxiety } & Sexual concerns & 0.29 \\
\hline & Tension reduction behaviors & 0.45 \\
\hline & Defensive avoidance & 0.34 \\
\hline & Dissociation & 0.29 \\
\cline { 2 - 3 } & Intrusive experiences & 0.38 \\
\cline { 2 - 3 } & Sexual concerns & 0.43 \\
\cline { 2 - 3 } & Tension reduction behaviors & 0.42 \\
\hline
\end{tabular}

Table 2: Association between Past Trauma, Post-9/11 Depression/Anxiety, and Mean TSI Subscale Scores.

dissociation, sexual concerns and tension reduction behaviors (Table 2 ). However, because the study did not survey reactions immediately after the attacks and cannot compare with outcomes a year later, an anniversary reaction cannot be confirmed. Similarly, Daly and colleagues [36] hypothesized that symptoms of PTSD, depression, anger, alcohol abuse, and functional impairment would increase on the first year anniversary of $9 / 11$. Using a sample of 108 disaster mental health workers, they found a significant increase in depressive symptoms and functional impairment on the first year anniversary of $9 / 11$.

\section{Protective factors}

Age and years of experience: In the SVH study, younger clinicians scored significantly higher on the TSI defensive avoidance subscale $(\mathrm{r}=-0.38 ; \mathrm{p}<0.05)$. This finding provides further support to other studies included in the review which found that age and/or fewer years of professional experience increased one's likelihood of developing symptoms of VT [33-35].

Religion/Spirituality: In the SVH study, religious participation was inversely related to TSI defensive avoidance scale $(-0.31 ; \mathrm{p}<0.05)$. It also indicated that frequency of religious participation may have a protective effect against VT. However, this finding was not supported by the Creamer and Liddle [35] study.

Marital status: The SVH study found that married mental health clinicians reported fewer symptoms of depression and fewer dysfunctional sexual behaviors in those TSI subscales $(r=-0.30$ for both subscales; $\mathrm{p}<0.05$ ) This finding was consistent with one study [33] demonstrating an inverse relationship between being married and VT among mental health workers who provided services to victims of the 9/11 terrorist attacks. Relationship status was not statistically significant in the other studies $[33,35]$.

\section{Supervision}

Mental health professionals who reported receiving individual supervision at least once a week had lower IES-r intrusion scores than those who received individual supervision less frequently $\left(X^{2}=3.85\right.$, $\mathrm{p}=0.05$ ). Professional support and supervision was not evaluated as a variable of interest in the other studies reviewed.

\section{9/11 Volunteer Activities}

The act of volunteering was not examined as a variable of interest in the SVH survey but it warrants inclusion in the list of protective factors, based on the findings of other studies identified in our review of the published literature, and because of its relevance. Despite Colarossi and colleagues' [34] finding that the provision of services specific to 9/11victims was positively related to depressive, anxiety and traumatic stress symptoms, the psychologists in the study of Eidelson and colleagues [37] identified participation in volunteer activities related to 9/11 as an important predictor of increased positive feelings about work. Further, they found that $54 \%$ of those who worked in close proximity to Ground Zero reported increased positive feelings about work. This may indicate that mental health workers can experience growth as a result of seeing a victim through to a full recovery based on their interventions; or that clinicians who were secondary or tertiary disaster victims of 9/11 were able to mitigate their own reactions to the attacks by focusing on helping others cope with the impact of the mass trauma.

\section{Discussion}

While literature on disaster psychiatry surged after $9 / 11$ [38], the empirical evidence on VT and the impact of disaster work on mental health providers has strikingly lagged behind. No one disputes the practical implications of addressing VT and ensuring the physical as well as the psychological safety of workers who deliver services to a community hit by a large-scale catastrophe. Project Liberty, launched after $9 / 11$, was the largest federal mental health response to a disaster in US history [39]. Based on the experience of the clinicians in Project Liberty who provided mental health services for three years, and on research evidence that mental health professionals may reduce their risk of VT by obtaining additional training and education related to traumatology [40], the federal government has included predeployment training on burnout, compassion fatigue, secondary traumatic stress, and vicarious traumatization [41-46] for all federal disaster crisis counseling programs. Modern disaster management that has emerged post-9/11 has renewed attention to the safety and wellness of disaster responders, including mental health providers. Federal predeployment trainings now include webinars and apps that has sections on provider self-assessment and provider self-care before, during and after disaster relief work. This is a step in the right direction in order to improve outcomes for mental health providers and mitigate the negative impact during times of widespread demand for disaster mental health services. However, without comprehensive and rigorous studies on VT specific to clinicians who provide an array of services to the distinct mental health needs in the post-disaster setting, various recommendations for training, self-assessment and personal care are limited and remain anecdotal [47-50].

Similar to previous research, this study found that having a history of personal trauma, less professional experience, and a caseload consisting of larger numbers of primary or secondary trauma victims increased the risk of VT. The results of the SVH study also provide support for previous research which identified having strong social supports, such as being married and having religious or spiritual affiliations, as protective factors against VT. Unlike other studies, however, the SVH study found that a history of anxious or depressive symptoms prior to 9/11 increased the risk of VT while increased workplace support and individual supervision decreased the risk of VT among mental health professionals who provided services to victims of $9 / 11[51,52]$.

\section{Limitations}

Methodological differences across the studies and small sample sizes may explain much of the variability between study findings; these factors, combined with the limited number of studies to draw from, render it difficult to identify clear risk and protective factors of VT among mental health workers who provided services to victims of $9 / 11$ beyond the SVH study. It is also challenging to compare the results because 
the terms "secondary traumatic stress" and "vicarious trauma" are used by some researchers interchangeably, while others argue that each has its own specific meaning and therefore its own special characteristics. While all of the studies reviewed in this paper reported some form of secondary psychological stress in mental health professionals, any differences between case definitions of "secondary traumatic stress" and "vicarious trauma" in these studies and the variability in instruments used to measure these differing concepts further complicate our ability to compare results. The SVH study may also be limited by selection bias; it is possible that the mental health workers who agreed to participate in the study may differ from those who did not. Finally, the SVH study may be limited by its cross-sectional design. A longitudinal design would allow for additional inferences about risk and protective factors of VT to be made.

Despite these limitations, it is evident that some mental health workers were at increased risk of developing symptoms of VT as a consequence of providing mental health services to victims of the 9/11 terrorist attacks. Similar susceptibility to occupational-related stress and emotional morbidity could arise in mental health clinicians responding to natural and technological disasters.

\section{Conclusion}

The literature on VT and disaster mental health response have yet to come together in longitudinal and comprehensive theoretically driven studies. Future research should address the overlapping concepts of VT and attempt to replicate as many of the independent variables as possible so as to improve understanding of the factors associated with VT in the context of disasters. This study identified many of the integral risk and protective factors for VT in mental health workers and a meta-analysis of the literature is warranted to facilitate the initiation of longitudinal studies that may further enhance comprehension and management of VT.

Our findings suggest that interventions such as increasing the frequency of individual supervision and maintaining a balanced caseload (particularly with younger, less experienced mental health workers and those with personal vulnerabilities) may reduce symptoms of VT among mental health workers who serve disaster victims.

\section{References}

1. Galea S, Vlahov D, Resnick H, Ahern J, Susser E, et al. (2003) Trends of probable post-traumatic stress disorder in New York City after the September 11 terrorist attacks. American Journal of Epidemiology 158: 514-524.

2. DiGrande L, Perrin MA, Thorpe LE, Thalji L, Murphy J, et al. (2008) Posttraumatic stress symptoms, PTSD, and risk factors among lower Manhattan residents 2-3 years after the September 22, 2001 terrorist attacks. Journal of Traumatic Stress 21: 264-273.

3. Galea S, Ahern J, Resnick H, Kilpatrick D, Bucuvalas M, et al. (2002) Psychological sequelae of the September 11 terrorist attacks in New York City. New England Journal of Medicine 346: 962-967.

4. Schlenger WE, Caddell JM, Ebert L, Jordan BK, Rourke KM, et al. (2002) Psychological reactions to terrorist attacks: findings from the National Study of Americans' Reactions to September 11. Journal of the American Medical Association 288: 581-588.

5. Silver RC, Holman EA, Mclntosh DN, Poulin M, Gil-Rivas V (2002) Nationwide longitudinal study of psychological responses to September 11. Journal of the American Medical Association 288: 1235-1244.

6. Fullerton CS, Ursano RJ, Reeves J, Shigemura J, Grieger T (2006) Perceived safety in disaster workers following $9 / 11$. Journal of Nervous and Mental Disease 194: 61-63.

7. Johnson SB, Langlieb AM, Teret SP, Gross R, Schwab M, ET AL. (2005) Rethinking first response: effects of the clean up and recovery effect on workers at the World Trade Center disaster site. Journal of Occupational and Environmental Medicine 47: 386-391.

8. Elwood LS, Mott J, Lohr JM, Galovski TE (2011) Secondary trauma symptoms in clinicians: A critical review of the construct, specificity, and implications for trauma-focused treatment. Clinical Psychology Review 31: 25-26.

9. Figley CR (1995a) Compassion Fatigue: Towards a new understanding of the costs of caring. In: Stamm BH (ed.) Secondary traumatic stress: Self care issues for clinicians, researchers, and educators. Baltimore, MD: Sidran Press.

10. Pearlman LA (1995) Self-care for trauma therapists: Ameliorating vicarious traumatization. In: Stamm BH (ed.) Secondary traumatic stress: Self-care issues for clinicians, researchers, and educators. Lutherville, MD: Sidran.

11. McCann IL, Pearlman LA (1990) Vicarious traumatization: A framework for understanding the psychological effects of working with victims. Journal of Traumatic Stress 3: 131-149.

12. Harrison RL, Westwood MJ (2009) Preventing vicarious traumatization of mental health professionals: Identifying protective practices. Psychotherapy 46: 203-219.

13. Hesse AR (2002) Secondary trauma: how working with trauma survivors affects therapists. Clinical Social Work Journal 30: 293-309.

14. Maslach C, Schaufeli WB, Leiter MP (2001) Job burnout. Annual Review of Psychology 52: 397-422.

15. Jenkins SR, Baird S (2002) Secondary traumatic stress and vicarious trauma: a validation study. Journal of Traumatic Stress 15: 423-432.

16. Neumann DA, Gamble SJ (1995) Issues in the professional development of psychotherapists: Countertransference and vicarious traumatization in the new trauma therapist. Psychotherapy 32: 341-347.

17. Pearlman LA, Mac Ian PS (1995) Vicarious trauma: an empirical study of the effects of trauma work on trauma therapists. Professional Psychology Research and Practice 26: 558-565.

18. Rosenbloom DJ, Pratt AC, Pearlman LA (1995) Helpers' responses to trauma work: Understanding and intervening in an organization. In: Stature $\mathrm{BH}$ (ed.) Secondary traumatic stress: Self-care issues for clinicians, researchers, and educators. Lutherville, MD: Sidran Press.

19. Brady JL, Guy JD, Poelstra PL, Browkaw B (1999) Vicarious traumatization, spirituality, and the treatment of sexual abuse survivors: A national survey of women psychotherapists. Professional Psychology Research and Practice 30: 386-393.

20. Steed L, Bicknell J (2001) Trauma and the therapist: The experience of therapists working with the perpetrators of sexual abuse. Australasian Journal of Disaster and Trauma Studies.

21. Way I, VanDeusen KM, Martin G, Applegate B, Jandle D (2004) Vicarious trauma: A comparison of clinicians who treat survivors of sexual abuse and sexual offenders. Journal of Interpersonal Violence 19: 49-71.

22. Bride BE, Figley CR (2009) Secondary trauma and military veteran caregivers Smith College Studies in Social Work 79: 314-329.

23. Voss Horrell SC, Holohan DR, Didion LM, Vance GT (2011) Treating traumatized OEF/OIF veterans: How does trauma treatment affect the clinician? Professional Psychology Research and Practice 42: 79-86.

24. Culver LM, McKinney BL, Paradise LV (2011) Mental health professionals experiences of vicarious traumatization in post-Hurricane Katrina New Orleans. Journal of Loss and Trauma 16: 33-42.

25. Wee DF, Myers D (2002) Stress responses of mental health workers following disaster: The Oklahoma City bombing. In: Figley CR (ed.) Treating Compassion Fatigue. New York, NY: Brunner-Routledge.

26. Eriksson CB, Vande Kamp H, Gorsuch R, Hoke S, Foy DW (2001) Trauma exposure and PTSD symptoms in international relief and development personnel. Journal of Traumatic Stress 14: 205-212.

27. Bride BE, Jones JL, MacMaster SA (2007a) Correlates of secondary traumatic stress in child protective service workers. Journal of Evidence Based Social Work 4: 69-80.

28. Nelson-Gardell D, Harris D (2003) Childhood abuse history, secondary traumatic stress, and child welfare workers. Child Welfare 82: 5-26.

29. Follette VM, Polusny MM, Milbeck K (1994) Mental health and law enforcement 
Citation: Quitangon G, St. Cyr K, Nelson C, Lascher S, DiFrancisci L, et al. (2016) Vicarious Trauma in Mental Health Professionals Following the 9/11 Terrorist Attacks. J Ment Disord Treat 2: 118. doi:10.4172/2471-271X.1000118

Page 5 of 5

professionals: trauma history, psychological symptoms, and impact of providing services to child sexual abuse survivors. Professional Psychology Research and Practice 25: 275-282.

30. Figley CR, Stamm BH (1996) Psychometric review of the compassion fatigue self test. In: Stamm BH (ed.) Measurement of stress, trauma, and adaptation. Lutherville, MD: Sidran Press.

31. Weiss DS, Marmar CR (1997) The Impact of Event Scale - Revised. In: Wilson JP, Keane TM (eds.) Assessing Psychological Trauma and PTSD: A Practitioner's Handbook. New York, NY: Guildford Press.

32. Briere J (1995) Trauma Symptom Inventory: Professional Manual. Odessa. FL: Psychological Assessment Resources.

33. Adams RE, Figley CR, Boscarino JA (2008) The Compassion Fatigue Scale: Its use with social workers following urban disaster. Res Soc Work Pract 18 : 238-250.

34. Colarossi L, Heyman J, Phillips M (2005) Social workers' experiences of the World Trade Center disaster: stressors and their relationship to symptom types. Community Mental Health Journal 41: 185-198.

35. Creamer TL, Liddle BJ (2005) Secondary traumatic stress among disaster mental health workers responding to the September 11 attacks. Journal of Traumatic Stress 18: 89-96.

36. Daly ES, Gulliver SB, Zimering RT, Knight J, Kamholz BW, et al. (2008) Disaster mental health workers responding to Ground Zero: one year later. Journal of Traumatic Stress 21: 227-230.

37. Eidelson RJ, D'Alessio GR, Eidelson JI (2003) The impact of September 11 on psychologists. Professional Psychology Research and Practice 34: 144-150.

38. Flynn BW,Norwood AE (2004) Defining Normal Psychological Reactions to Disaster. Psychiatric Annals 34: 597-602.

39. Naturale A (2015) How do we understand disaster-related vicarious trauma secondary traumatic stress, and compassion fatigue? In G. Quitangon\& M Evces (Eds.). Vicarious Trauma and Disaster Mental Health: Understanding Risks and Promoting Resilience. New York, NY: Routledge.

40. Pearlman LA, Saakvitne KW (1995b) Treating therapists with vicarious traumatization and secondary traumatic stress disorders. In: Figley CR (ed.)
Compassion fatigue: Coping with secondary traumatic stress disorder in those who treat the traumatized. Bristol, PA: Brunner/Mazel.

41. Substance Abuse and Mental Health Services Administration Disaster Technical Assistance Center (2013).

42. Bride BE, Radey M, Figley CR (2007b) Measuring compassion fatigue. Clinica Social Work Journal 35: 155-163.

43. Briere J, Elliott DM (1998) Clinical utility of the Impact of Event Scale: Psychometrics in the general population. Assessment 5: 171-180.

44. Catherall DR (1995) Coping with secondary traumatic stress: The importance of the therapist's professional peer group. In: Stamm BH (ed.) Secondary traumatic stress: Self-care issues for clinicians, researchers, and educators. Lutherville, MD: Sidran

45. Figley CR (1995b) Compassion Fatigue: Coping with secondary traumatic stress disorder. New York, NY: Brumner/Mazel.

46. Hellman ID, Morrison TL, Abramowitz SI (1987)Therapist experience and the stresses of psychotherapeutic work. Psychotherapy 24: 171-177.

47. Horowitz MJ, Wilner M, Alverez W (1979) Impact of Event Scale: A measure of subjective stress. Psychosomatic Medicine 41: 209-218.

48. McDevitt-Murphy ME, Weathers FW, Adkins JW (2005) The use of the Trauma Symptom Inventory in the assessment of PTSD symptoms. Journal of Traumatic Stress 18: 63-67.

49. Runtz MD, Roche DN (1999) Validation of the Trauma Symptom Inventory (TSI) in a Canadian university sample. Child Maltreatment 4: 69-80.

50. Schuster MA, Stein BD, Jaycox L, Collins RL, Marshall GN, et al. (2001) A national survey of stress reactions after the September 11,2001, terrorist attacks. New England Journal of Medicine 345: 1507-1512.

51. Trippany RL, White Kress VE, Wilcoxon SA (2004) Preventing vicarious trauma: What counselors should know when working with trauma survivors. Journal of Counseling and Development 82: 31-37.

52. Weiss DS (2004) The Impact of Event Scale - Revised. In: Wilson JP, Keane TM (eds.) Assessing Psychological Trauma and PTSD: A Practitioner's Handbook. New York, NY: Guildford Press. 